\title{
Hospital Care for Newborn Babies: Quality Assessment, A Systematic Review
}

\author{
Hossein Jabbari, ${ }^{1}$ Somayae Abdollahi Sabet, ${ }^{1, *}$ and Mohammad Heidarzadeh ${ }^{2}$ \\ ${ }^{1}$ Department of Community Medicine, Tabriz University of Medical Sciences, Tabriz, IR Iran \\ ${ }^{2}$ Department of Pediatrics, Tabriz University of Medical Sciences, Tabriz, IR Iran \\ ${ }^{*}$ Corresponding author: Somayae Abdollahi Sabet, Department of Community Medicine, Tabriz University of Medical Sciences, Tabriz, IR Iran. E-mail: somayaesabet@gmail.com
}

Received: August 12, 2015; Accepted: August 17, 2015

\begin{abstract}
Context: Neonatal mortality rate is declining globally. The aim of the present study is to identify relevant indicators for assessing newborn care in hospitals by a systematic review.

Evidence Acquisition: A search on electronic data base and manual searches of personal files for studies on quality indicators of newborn care were carried out. Searching 9 bibliographic databases, we found 85 articles of which 22 exactly related ones were selected and studied. Hand search yielded 1 record were also searched and 2 records were included.

Results: A list of 87 structure, process and outcome indicators was formulated from the articles. Also 26 excess measures were identified in gray literature. After removing duplicates, and categorizing in 3 domains, 18 measures were input, 41 process and 34 outcome measures. Conclusions: These 93 indicators provide a framework for assessing how well the hospitals are providing neonatal care. These measures should be discussed in each context expert panels to address nationally applicable indices of neonatal care and may be adapted for local health settings.
\end{abstract}

Keywords: Quality Indicators; Neonatal Care; Newborn Care

\section{Context}

Neonatal mortality rate is declining globally and fell from 40 to 33 deaths per 1,000 live births between 1990 and 2013. In Iran it fell from 27 to 10 in this time period and accounts for more than half of the under-5-year child mortality (1-3). Evidences from trend studies show that neonatal mortality decline has slowed down and neonatal deaths account for a larger share of U5MR (4).

The office for neonatal health in Iranian ministry of health developed and implemented various plans to improve the healthy and also sick newborn care. Availability and access to care is essential but not sufficient to get desirable outcome. The quality of care plays crucial role.

Health care systems seeking quality and accountability need to assess the performance of facilities and monitoring changes to display trends in measures. Assessments are needed at every level of health care from community setting to level III referral hospitals. The point is to identify what should be assessed. An author introduced "quality black box" because it is extremely difficult to exactly measure what must be measured as a quality indicator (5). Donabedian's categorization of measurement of quality consisting of indicators for structure (personal characteristics and institutional features), process (activities in providing care), and outcome (result of care) is an accepted approach (6).

\section{Evidence Acquisition}

Nine bibliographic data bases, 4 Iranian (SID, IranDoc, Magiran, medlib) and 5 international (Pubmed, scienceDirect, googlescholar, Scopus and Cochrane), were searched. It was limited by publication time 1990 - 2013. Multiple combinations of keywords were used: neonatal care, perinatal care, newborn care, quality, quality indicators, evaluation, evaluation mechanism, assessment, quality assessment and performance. Gray literature search was done on the world health organization (WHO), American academy of Pediatrics and Iranian Ministry of Health websites. Manual search was carried out for unpublished materials simultaneously. Researchers reviewed the title and abstracts independently and in a sitting selected abstracts which did not met exclusion criteria for full text review. Exclusion criteria were: not reporting neonatal care measures and non-Persian/English language. At the next stage, full texts were reviewed. References cited in retrieved articles were also searched and screened. Those papers that actually met the inclusion criteria were included in the study (Table 1$)$.

Copyright (C) 2015, Growth \& Development Research Center. This is an open-access article distributed under the terms of the Creative Commons Attribution-NonCommercial 4.0 International License (http://creativecommons.org/licenses/by-nc/4.0/) which permits copy and redistribute the material just in noncommercial usages, provided the original work is properly cited. 
Table 1. Overview of the Included Studies

\begin{tabular}{lll}
\hline Author/s Country Study Design & Quality Measure & Publication \\
Date
\end{tabular}

Profit et al. USA Delphi Antenatal steroids, timely retinopathy of prematurity exam, late onset sepsis, 201 hypothermia on admission, pneumothorax, growth velocity, oxygen at 36 weeks postmenstrual age, any human milk feeding at discharge, in-hospital mortality

\begin{tabular}{|c|c|c|c|c|c|}
\hline Kaplan et al. & USA & HIS data analysis & Surfactant use rate for premature babies & 2011 & (8) \\
\hline Neogi et al. & India & $\begin{array}{l}\text { Cross sectional } \\
\text { survey }\end{array}$ & $\begin{array}{l}\text { Nurse: bed ratio, Doctor: bed ratio, Reported time (months) for repair of } \\
\text { essential equipment, Asepsis score, Average duration (days) of stay, Bed } \\
\text { Occupancy rate }\end{array}$ & 2011 & (9) \\
\hline $\begin{array}{l}\text { Nowakowski } \\
\text { et al. }\end{array}$ & USA & $\begin{array}{l}\text { Cross sectional } \\
\text { survey }\end{array}$ & $\begin{array}{c}\text { Regulation of regionalization programs, data surveillance, review of adverse } \\
\text { events }\end{array}$ & 2012 & $(10)$ \\
\hline Toome et al. & Estonia & $\begin{array}{l}\text { Population based } \\
\text { reports }\end{array}$ & $\begin{array}{l}\text { Proportion of infants born by cesarean, received antenatal corticosteroids, } \\
\text { maternal antibiotics, and surfactant }\end{array}$ & 2012 & (11) \\
\hline Neogi et al. & India & Review & $\begin{array}{l}\text { Regionalization of perinatal care, staff: bed ratio, existence of residential } \\
\text { medical staff, NMR }\end{array}$ & 2012 & (12) \\
\hline Gale et al. & UK & $\begin{array}{l}\text { Population-wide } \\
\text { observation }\end{array}$ & $\begin{array}{l}\text { Volume of neonatal specialist care ( } \geq 2000 \text { neonatal intensive care days } \\
\text { annually), having an acute transfer (within the first } 24 \text { hours after birth) } \\
\text { and/or a late transfer (between } 24 \text { hours and } 28 \text { days after birth) to another } \\
\text { hospital, assessed by change in distribution of transfer category ("none," } \\
\text { "acute," "late"), and babies from multiple births separated by transfer }\end{array}$ & 2012 & $(13)$ \\
\hline $\begin{array}{l}\text { Oestergaard } \\
\text { et al. }\end{array}$ & $\begin{array}{l}\text { Switzer- } \\
\text { land }\end{array}$ & $\begin{array}{l}\text { Neonatal } \\
\text { mortality data } \\
\text { base of } 38 \\
\text { countries }\end{array}$ & NMR trends & 2011 & (14) \\
\hline $\begin{array}{l}\text { Tamburlini } \\
\text { et al. }\end{array}$ & Italy & Survey & $\begin{array}{l}\text { Existence of basic amenities, existence of essential drugs and equipment, } \\
\text { hygienic practice, existence of surveillance system }\end{array}$ & 2011 & (15) \\
\hline $\begin{array}{l}\text { Marston } \\
\text { et al. }\end{array}$ & UK & Review & $\begin{array}{l}\text { skilled care before/during/after birth and maternal/newborn mortality/ } \\
\text { morbidity }\end{array}$ & 2013 & $(16)$ \\
\hline $\begin{array}{l}\text { Tamburlini } \\
\text { et al. }\end{array}$ & Italy & $\begin{array}{l}\text { Before-after } \\
\text { observational } \\
\text { study }\end{array}$ & $\begin{array}{l}\text { No. of nurses, doctors, drugs, equipment: bed, normal delivery/ section } \\
\text { proportion, thermal control, use of Apgar score, promotion of breastfeeding, } \\
\text { neonatal resuscitation, mothers more involved in neonatal care, training } \\
\text { more staff in effective perinatal care }\end{array}$ & 2013 & (17) \\
\hline Phibbs et al. & USA & Record linkage & $\begin{array}{l}\text { The percentage of very-low-birth-weight deliveries in level } 3 \text { hospitals, } \\
\text { mortality: volume of NICU }\end{array}$ & 2007 & (18) \\
\hline $\begin{array}{l}\text { Rogowski } \\
\text { et al. }\end{array}$ & UK & $\begin{array}{l}\text { Retrospective } \\
\text { observational }\end{array}$ & Mortality of VLBW before discharge to home in each hospital level & 2004 & $(19)$ \\
\hline Saugstad & Norway & Review & $\begin{array}{l}\text { Regionalization implementation, promotion of breast feeding, investing in } \\
\text { equipment and staff, evidence-based treatment, training programs }\end{array}$ & 2011 & $(20)$ \\
\hline $\begin{array}{l}\text { Lindmark } \\
\text { and Lang- } \\
\text { hoff-Roos }\end{array}$ & Sweden & $\begin{array}{l}\text { Retrospective } \\
\text { observational }\end{array}$ & $\begin{array}{l}\text { Fetal mortality rate, neonatal mortality rate, infant mortality rate. } \\
\text { Distribution of birth weight, distribution of gestational age, prevalence of } \\
\text { congenital anomalies, distribution of Apgar score at } 5 \text { min }\end{array}$ & 2004 & $(21)$ \\
\hline Marcin & USA & $\begin{array}{l}\text { Retrospective } \\
\text { observational }\end{array}$ & $\begin{array}{c}\text { NICU mortality rate, standardized mortality ratio, standardized NICU length } \\
\text { of stay ratio }\end{array}$ & 2000 & $(22)$ \\
\hline
\end{tabular}



existence of residential pediatrician/neonatologist, FHR monitoring during labor, partograph filling for vaginal deliveries, parent's training before discharge, resuscitation form filling for performed ones, fetomaternal transfer rate, neonatal transform organized by transfer guide, hypoxia on admission, mean/median duration of NICU stay, mean/median duration of mechanical ventilation in NICU, proportion of newborns who receipt required follow up, perinatal mortality rate, primary c/s rate, repeat c/s rate, mother readmission rate

$\begin{array}{llc}\begin{array}{l}\text { Pollack and USA } \\ \text { Koch }\end{array} & \begin{array}{c}\text { Multiple center } \\ \text { cohort }\end{array} & \begin{array}{c}\text { Bronchopulmonary dysplasia (BPD), periventricular/intraventricular } \\ \text { hemorrhage or periventricular leukomalacia (PIVH/PVL), and retinopathy of } \\ \text { prematurity (ROP). duration of hospital stay and days on a ventilator for those } \\ \text { infants who received mechanical ventilation, organizational measures: qual- } \\ \text { ity of teamwork and leadership, degree of relationships and communications } \\ \text { within the NICU, degree of coordination, perceived unit/team effectiveness, } \\ \text { authority, quality of conflict resolution, job satisfaction }\end{array} \\ & \end{array}$

85 articles identified through data base searching
1 record identified through other sources

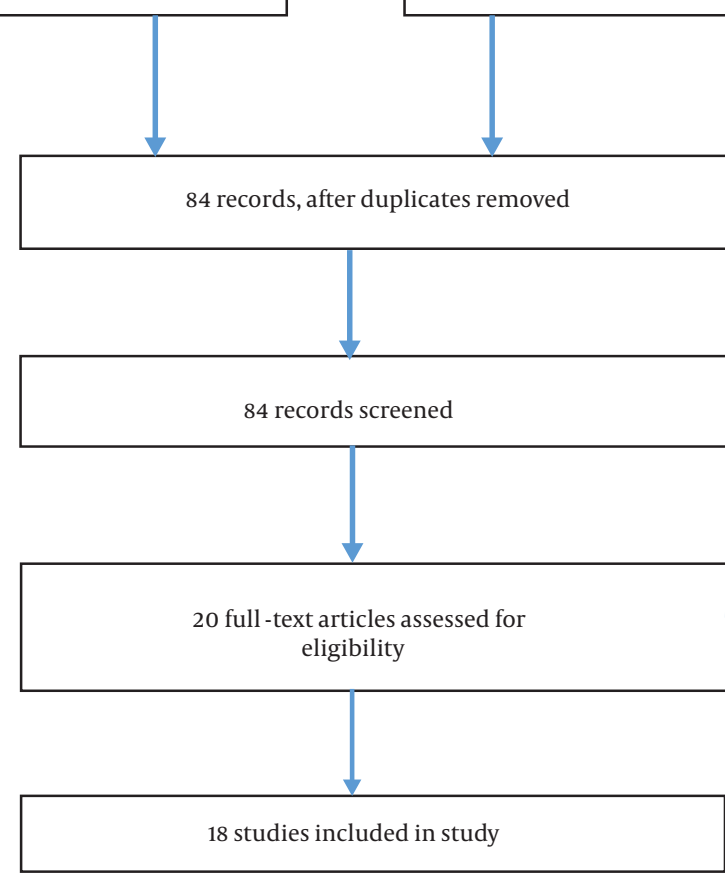

\section{Results}

The process of searching bibliographic data bases, selection and number of papers retrieved in each phase is shown in Figure 1.

Reviewing the papers, 87 indicators were extracted. Among them, 13 were duplicates. Remaining measures were classified in input $(n=14)$, process $(n=31)$, and outcome measures $(n=29)$. Assessing the hand searched documents 25 indicators were derived of which 7 were duplicates. Considering the 18 input indices, 41 process and 34 output indices were obtained (Table 2 ). 
Table 2. Retrieved Neonatal Care Measures, Categorized Using Donabedian Model

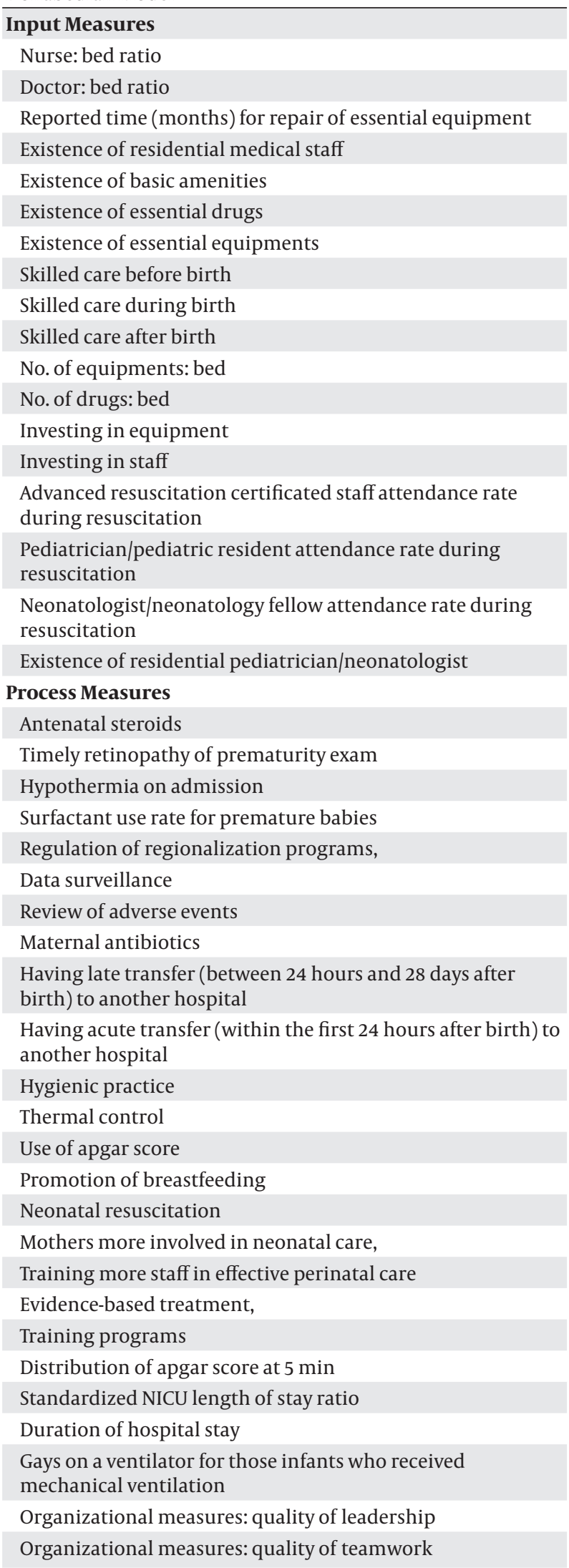

Degree of relationships and communications within NICU Degree of coordination

Authority, quality of conflict resolution

Job satisfaction

Bed occupancy rate

Volume of neonatal specialist care $(\geq 2000$ neonatal intensive care days annually)

FHR monitoring during labor

Partograph filling for vaginal deliveries

Parent's training before discharge

Resuscitation form filling for performed ones

Fetomaternal transfer rate

Neonatal transform organized by transfer guide

Hypoxia on admission

Mean/median duration of NICU stay

Mean/median duration of mechanical ventilation in NICU

Proportion of newborns who accept required follow up

\section{Outcome Measures}

Late onset sepsis

Pneumothorax

Growth velocity

Oxygen at 36 weeks postmenstrual age

Any human milk feeding at discharge

In-hospital mortality

Asepsis score

Average duration (days) of stay

Proportion of infants born by cesarean

NMR

NMR trends

Maternal mortality

Maternal morbidity

Neonatal morbidity

Normal delivery proportion

Section proportion

The percentage of very-low-birth-weight deliveries

Mortality: volume of NICU

Mortality of VLBW before discharge home in each hospital level

Fetal mortality rate

Distribution of birth weight

Distribution of gestational age

Prevalence of congenital anomalies

Standardized mortality ratio

Bronchopulmonary dysplasia (BPD)

Retinopathy of prematurity (ROP)

Periventricular/intraventricular hemorrhage

Periventricular leukomalacia

Perceived unit/team effectiveness

Perinatal mortality rate

Primary c/s rate

Repeat c/s rate

Mother readmission rate

Case fatality rate for neonatal disease 


\section{Conclusions}

This is the systematic review with the main aim of providing a tool for evaluating quality of neonatal care in hospitals at any level. Evaluation is essential for improving provided health care and also comparing different settings. We perused the original and reviewed papers for the recommended indicators. We considered infrastructure, equipment and staff as input, admission, treatment, care practices, referral, discharge and follow up as process indices. Newborn health status, care outcome and consequences were categorized as outcome indicators.

The structural factors are essential for quality of care in health care facilities, yet it is clear that these aspects are not sufficient to assure high quality, as currently, process and outcome measures are more emphasized.

As can be seen, much of the proposed or applied indicators are in the process group, indicating the importance of components of good care. According to this criterion, a health care setting should be assessed by reviewing medical records, direct observations and interviews with care provider and recipients to determine to what extent the provided care is acceptable according to the level of facility. Nevertheless there are three noticeable points regarding these indicators. First the measuring, which is more complicated than the other two categories and require assessing multiple sources for data extraction-the accuracy of which is questionable-that lessen the feasibility. The other point is that the standard care is so variable among different areas of the world and in one and the same place would differ over time. Finally they do not indicate whether the patient is better off.

Actually some authors recommend to choose those process measures that scientific evidence illustrates they link to improved outcomes $(25,26)$.

Outcome measures refer to effectiveness of the care provided. They consist of early (proximal) and late (distal) outcomes. Although such measures have traditionally been mortality and morbidity, outcomes research in recent years has expanded the measures to include patients' perception of their health status and the services (technical care and also interpersonal relationship) that they receive. The point that must be considered is that determining health care outcome at discharge will miss some complications that appear just after discharge and we should think of recording patient's data after discharge at follow up care.

Presumably there are some indicators that haven't been mentioned and some of which do not fit the Iranian settings. Therefore, qualitative studies are required to obtain the expert's opinion and integrate both results to make a list of appropriate measures for evaluation of quality of perinatal care provided in Iranian settings.

\section{References}

1. UNICEF IROI. The State of The World's Children 2015 Country Statistical tables. UNICEF; 2014. Available from: http://www.unicef.org/ infobycountry/iran_statistics.html\#0.

2. UNICEF. UNICEF Annual Report 2013. UNICEF; 2014. Available from: http://www.unicef.org/publications/index_73682.html.

3. World Health Organization . UNICEF, WHO, World Bank, UN-DESA
Population Division. WHO; 2014. Available from: http://www.who. int/maternal_child_adolescent/documents/levels_ trends_ child_mortality_2014/en/.

4. You D, Jones G, Hill K, Wardlaw T, Chopra M. Levels and trends in child mortality, 1990-2009. Lancet. 2010;376(9745):931-3.

5. Lorch SA. Quality measurements in pediatrics: what do they assess? JAMA Pediatr. 2013;167(1):89-90.

6. Rossi PH, Lipsey MW. Evaluation: A Systematic Approach. 5 ed. Newbury Park, CA: Sage ; 2004.

7. Profit J, Gould JB, Zupancic JA, Stark AR, Wall KM, Kowalkowski MA, et al. Formal selection of measures for a composite index of NICU quality of care: Baby-MONITOR. J Perinatol. 2011;31(11):702-10.

8. Kaplan HC, Lorch SA, Pinto-Martin J, Putt M, Silber JH. Assessment of surfactant use in preterm infants as a marker of neonatal intensive care unit quality. BMC Health Serv Res. 2011;11:22.

9. Neogi SB, Malhotra S, Zodpey S, Mohan P. Assessment of special care newborn units in India.J Health Popul Nutr. 2011;29(5):500-9.

10. Nowakowski L, Barfield WD, Kroelinger CD, Lauver CB, Lawler $\mathrm{MH}$, White VA, et al. Assessment of state measures of risk-appropriate care for very low birth weight infants and recommendations for enhancing regionalized state systems. Matern Child Health J. 2012;16(1):217-27.

11. Toome L, Ringmets I, Andresson P, Ilmoja ML, Saik P, Varendi H. Changes in care and short-term outcome for very preterm infants in Estonia. Acta Paediatr. 2012;101(4):390-6.

12. Neogi SB, Malhotra S, Zodpey S, Mohan P. Does facility based newborn care improve neonatal outcomes? A review of evidence. Indian Pediatr. 2012;49(8):651-8.

13. Gale C, Santhakumaran S, Nagarajan S, Statnikov Y, Modi N, Neonatal Data Analysis U, et al. Impact of managed clinical networks on NHS specialist neonatal services in England: population based study. BMJ. 2012;344:e2105.

14. Oestergaard MZ, Inoue M, Yoshida S, Mahanani WR, Gore FM, Cousens S, et al. Neonatal mortality levels for 193 countries in 2009 with trends since 1990: a systematic analysis of progress, projections, and priorities. PLoS Med. 2011;8(8):e1001080.

15. Tamburlini G, Siupsinskas G, Bacci A, Maternal. Neonatal Care Quality Assessment Working G. Quality of maternal and neonatal care in Albania, Turkmenistan and Kazakhstan: a systematic, standard-based, participatory assessment. PLoS One. 2011;6(12):e28763.

16. Marston C, Renedo A, McGowan CR, Portela A. Effects of community participation on improving uptake of skilled care for maternal and newborn health: a systematic review. PLoS One. 2013;8(2):e55012.

17. Tamburlini G, Yadgarova K, Kamilov A, Bacci A, Maternal. Neonatal Care Quality Improvement Working G. Improving the quality of maternal and neonatal care: the role of standard based participatory assessments. PLoS One. 2013;8(10):e78282.

18. Phibbs CS, Baker LC, Caughey AB, Danielsen B, Schmitt SK, Phibbs RH. Level and volume of neonatal intensive care and mortality in very-low-birth-weight infants. N Engl J Med. 2007;356(21):2165-75.

19. Rogowski JA, Horbar JD, Staiger DO, Kenny M, Carpenter J, Geppert J. Indirect vs direct hospital quality indicators for very lowbirth-weight infants. JAMA. 2004;291(2):202-9.

20. Saugstad OD. Reducing global neonatal mortality is possible. Neonatology. 2011;99(4):250-7.

21. Lindmark G, Langhoff-Roos J. Regional quality assessment in perinatal care. Semin Neonatol. 2004;9(2):145-53.

22. Marcin JP, Pollack MM. Review of the methodologies and applications of scoring systems in neonatal and pediatric intensive care. Pediatr Crit Care Med. 2000;1(1):20-7.

23. Heidarzade A. FGD on neonatal care indices in Iran [Unpublished work]. Gilan Medical University; 2010.

24. Pollack MM, Koch MA, N. IH-District of Columbia Neonatal Network. Association of outcomes with organizational characteristics of neonatal intensive care units. Crit Care Med. 2003;31(6):1620-9.

25. Mant J, Hicks N. Detecting differences in quality of care: the sensitivity of measures of process and outcome in treating acute myocardial infarction. BMJ. 1995;311(7008):793-6.

26. Wennberg JE. Unwarranted variations in healthcare delivery: implications for academic medical centres. BMJ.2002;325(7370):961-4. 